Canadian Journal of Family and Youth, 10(2), 2018, pp 67-84

ISSN 1718-9748 (C) University of Alberta

http://ejournals.library.ualberta.ca/index/php/cjfy

\title{
Bridging Cultures Over-Under: Digital Navigation to Create Liminal Spaces of Possibility
}

\author{
Michelle Hogue and Joanne Forrest
}

\begin{abstract}
In this paper, we as educators of Indigenous students transitioning into post-secondary education, reflect on our collaborative pilot project: Bridging Cultures Over-Under, a connection of Indigenous students in similar preparation for university programs at the University of Lethbridge in Lethbridge, AB, Canada, and at Batchelor Institute in Darwin, NT, AU. Unbeknownst to the students, the story of attempted assimilation of Indigenous peoples in both countries, and the resultant socio-economic conditions, is both parallel and similar. Through Skype sessions, Indigenous students in polar opposite countries shared their own experiences, culture, history, stories, dreams and desires and some of their academic work. The goal was to understand their shared experience and further build on these relationships so they might learn from and support each other through peer mentoring. Outcomes of this project have lead to a continued connection and the development of a secure Facebook site so that the students can further build their relationships and develop a more extensive network as they continue on their academic journey.
\end{abstract}

Michelle Hogue is an Associate Professor at the University of Lethbridge and is a Coordinator of the First Nations’ Transition Program. She is a person of Métis heritage and is passionate about enabling Indigenous academic success through early engagement and retention in ways that bridge cultures and attend to Indigenous ways of knowing and learning (IWKL). Her work explores enabling engagement, retention and success through integrated and inter-related methodological approaches that are inclusive of culture. As such, her teaching and research focus on building bridges between Indigenous and Western ways of knowing and learning using culturally relevant and innovative methodological approaches that blend required curricular and institutional demands with methodological teaching and learning practices such as hands-on-practical and applied learning, project-based learning, narrative, drama and music; ways in that attend to IWKL. Michelle works in the community with youth as well as at the post-secondary level because early and sustained engagement through mentorship is key to retention. Importantly, she also works to enable non-Indigenous educators and researchers to create space in their practice for IWKL. Currently, her work explores best practices in Canada, Australia and New Zealand to develop an inclusive, culturally responsive teaching practice and curricula through the philosophy of Bridging Cultures: Two-Eyed Seeing for Both Ways Knowing to enable Indigenous academic success. Major publications include: Hogue, M. (2018). Dropping the “T” from CAN'T: Enabling Aboriginal post-secondary success in science \& mathematics. Vernon, BC: J Charlton Press; Hogue, M. (2016). Aboriginal ways of knowing, the 21st century learner and STEM success. in education, 22(1), 161-172; and Hogue, M. (2014). Let's do it first and talk about it later: Rethinking post-secondary science education for Aboriginal learners. in education, 19(3), Spring 2014, Special Issue, Part I: Indigenous Education, 137-151.

Joanne Forrest is a Lecturer in the Preparation for Tertiary Success (PTS) program (Division of Higher Education and Research) on the Casuarina Campus. The PTS program is a tertiary enabling course with an exclusively Aboriginal and Torres Strait Islander learner cohort, a beginning researcher and forever life-long learner. Joanne spent her early years on the North Island of New Zealand and then grew up on the beautiful beaches of the Gold Coast in Queensland. She is now based in Darwin in the Northern Territory. Fortunate 


\section{Hogue and Forrest}

enough to have travelled a great deal of the globe, she has a genuine curiosity for people's stories: what it is that makes them unique and what it is that makes people who they are because of, or in spite of, their histories. As an educator, Joanne is passionate about exploring educationally-focused research, leadership, teaching and curriculum development opportunities. She has taught in Australia and internationally. Her youngest student was three and her oldest student so far was 86. They have all taught her so much as part of her own learning journey. Joanne's interests are in educational learning designs and practices that enable all learners access to equitable and quality educational environments and experiences. Learner identity for academic success is an area of particular focus. 
Bridging Culture Over-Under

\section{Introduction}

As educators of Indigenous university students on opposing sides of the globe, we, Michelle Hogue of the University of Lethbridge ( $U$ of L) and Joanne Forrest of Batchelor Institute located at the Charles Darwin University (CDU) campus, and our students in our respective transition programs, reflect on our collaborative pilot project: Bridging Cultures Over-Under. With the increasing demographic of young Indigenous students entering into the education system, it is critical that we build culturally responsive bridges between Indigenous Ways of Knowing and Learning (IWKL) and Western Ways of Knowing and Learning (WWKL) that build capacity and enable Indigenous academic success in this $21^{\text {st }}$ century. Thus, the goal of this pilot project and beginning collaboration was to share our knowledge, experience, and resources, and find ways of working effectively to best support Indigenous learners in their preparation for university. Through Skype sessions, our students connected and shared their own experiences with the goal to further build on these relationships so they might learn from and support each other through peer mentoring. Outcomes of this project have lead to the development of a secure Facebook site so that the students can further build on this connection and develop a more extensive network as we continue the project with our 2017-2018 cohorts over-under. 


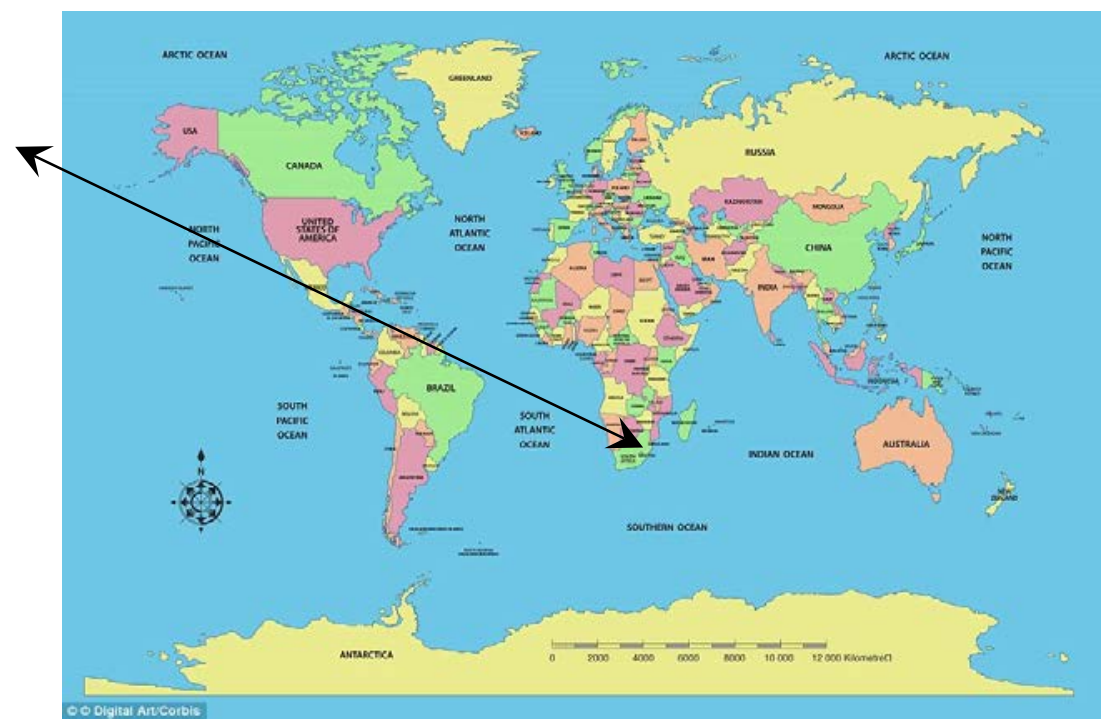

Figure 1. Map of the two locations.

Such a language would be...one that grows in the middle.

(Ted Aoki, 1993)

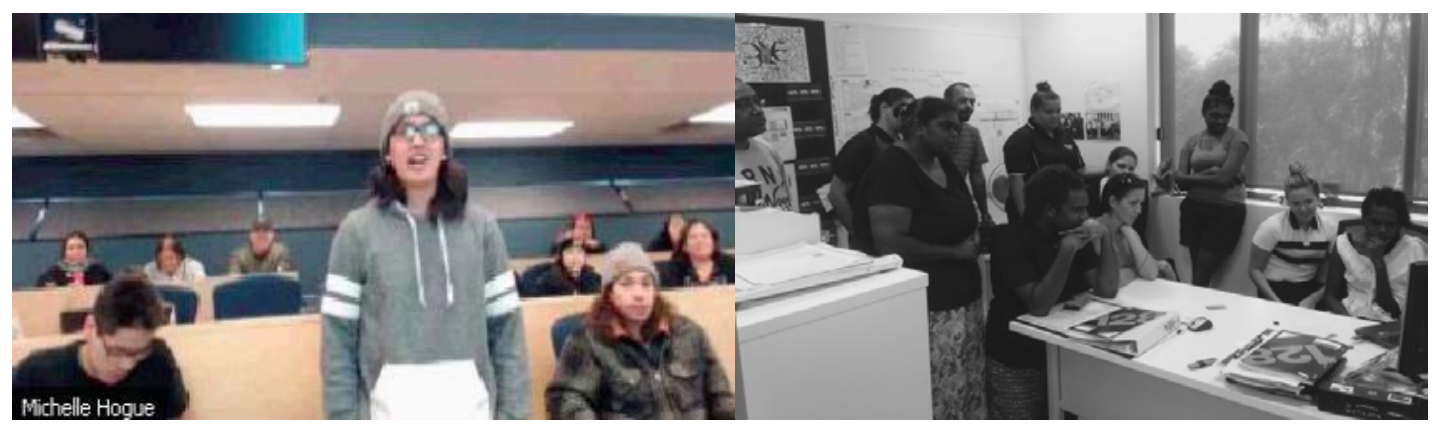

Figure 2. FNTP Students, U of L, Lethbridge, AB, CA (left). PTS Students, Batchelor Institute at CDU, Darwin, NT, AU (right).

What I really liked about skyping with the students in Australia is that it made it so real; skyping really brought them to life. At first it was a bit scary because they were up on a screen and seemed larger than life and it was sort of weird to be talking to a screen but once we started talking it was so cool because it was like we could have a real conversation. I learned so much and wish we could have done this for the whole year. It was way better than reading about their culture in a book that is for sure. We got to hear their stories in the real (FNTP student, 2017).

Yesterday's communication with the First Nations students of Canada would have to be the highlight of this block for me. Hearing about their visions for the future was not only interesting but also inspiring. Learning what a 'reserve' is was a shock for me and made me more inquisitive about Canadian First Nations People. The interaction between me and fellow students was also something that has made me feel more relaxed and comfortable, being able to relate to them (even thought we were all nervous at the beginning). Also learning about them and where they come from was 
something that I believe has helped all of us. Sadly, our stories of assimilation are similar (PTS student, 2017).

\section{Building Bridges}

Michelle is an associate professor and scholar of Métis heritage while Joanne is a non-Indigenous Australian lecturer and educator. During Michelle’s visit to Darwin, Australia in 2016, we learned our programs were similar in nature in that they are transition programs intended to provide a solid foundation of courses and skills for Indigenous ${ }^{1}$ students who have not completed secondary school, been away from academics for some time, or who might not have the full qualifications necessary to enter directly into the postsecondary degree of their choice. Given the polarity of our locations, we were fascinated by our similar experiences and the parallel, yet unknown, Indigenous experience, and felt there was much our students and we as educators could learn from each other. This initiated the building of relationships between the two programs through classroom Skype sessions. The basis of this unique professional relationship and friendship is the foundation for an ongoing collaboration between the two institutions to investigate how we might reframe ideological standpoints to navigate, shape, and implement methodological approaches that best support Indigenous student learning from a Two-Eyed Seeing ${ }^{2}$ (Bartlett, 2017; Bartlett, Marshall, \& Marshall, 2012), Both-Ways Knowing (Ober, 2009; Ober \& Bat, 2007) perspective.

Outcomes will provide information and materials for both Indigenous and non-Indigenous educators and researchers investigating best practices for engaging, enabling, and retaining

\footnotetext{
${ }^{1}$ In Australia the Indigenous peoples are the Aboriginal and the Torres Strait Islander (ATSI) people while in Canada, the Indigenous peoples are diverse and collectively referred to as the First Nations, Métis, and Inuit (FNMI) peoples. For this paper we will refer to our respective original peoples Indigenous peoples.

${ }^{2}$ Learn to see from one eye with the best in Indigenous knowledge and ways of knowing, and from the other eye with the best in Western (or mainstream) knowledge and ways of knowing ... and LEARN to use both these eyes together for the benefit of all (Bartlett, 2017).
} 
Hogue and Forrest

Indigenous students. Digital connection such as Facebook builds and maintains relationships and is certainly a format most youth are familiar with, but importantly digital capacity building is critical for youth empowerment and is changing the landscape of Indigenous education (Singleton et al, 2009; Whiteduck, 2010). Digital technologies are hands-on learning by doing, a way of learning key to IWKL and is the foundation of our over-under project.

\section{Our Enabling Programs}

Both the First Nations' Transition Program (FNTP) at the University of Lethbridge (U of L), and Preparation for Tertiary Success (PTS) at Batchelor Institute (BI) are intended to provide a solid foundation of academic skills for Indigenous students who have not completed secondary schooling, who have been out of school for some time, or who might not have the academic qualifications or confidence to enter directly into their university program of choice. The FNTP is a full-year program whereas the PTS program can be taken as either a six-month or a twelve-month program depending on the entering student's academic level. An important component of both programs is the cohort model, where a small group of Indigenous students stay together for the entire program thus providing a community of co-learners. While the FNTP draws largely from a localized community who are often known to each other or connected through familial networks, the PTS draws from a diverse spread of Indigenous learners local to Darwin and from across remote communities in the Northern Territory and other parts of Australia. PTS students from outside Darwin have the option to (and often do) stay in student accommodations on the university campus, whereas the students in the FNTP either commute to the university from the community or live within the city; rarely do they live in residence. The key focus of both programs is on a core curriculum; small class sizes; personal relationships; academic, personal, and cultural supports; and culturally informed instructors. In addition to developing a strong academic 
foundation moving forward, both programs importantly are intended to connect Indigenous students, who come from similar backgrounds and who face similar challenges, together such that they may develop strong peer and academic relationships and networks for their future academic journey.

\section{The Historical Context: Residential and Mission Schools}

The historical plight of the Indigenous peoples in Canada and Australia is sadly a parallel story (O’Connor, 2000), one that has had large negative socioeconomic repercussions for both countries’ Indigenous people. Both the Canadian and Australian governments attempted to assimilate their Indigenous peoples into the dominant, largely white, European settler population under the guise of “nation building” (Getches, Wilkinson, \& Williams, 1993) through the erasure of Indigenous identity (Howard-Wagner \& Kelly, 2011). In Canada, this was first attempted by the failed industrial schools in the late 1800s and later by the nearly 100 government-mandated church-run residential schools (Getches, Wilkinson, \& Williams, 1993; Miller, 1989; O’Connor, 2000), the last of which closed in Saskatchewan in 1996 (Truth \& Reconciliation Report [TRC], 2015). Under the Indian Act and its numerous amendments (Merasty/Carpenter, 2015; Titley, 1986), it was the law that Indian children between the ages of 7 to 15 be removed from their families to attend residential school. This law was enforced through a system of fines and threats of imprisonment by truant officers who, at times, forcibly removed children, some as young as four, from their families (Titley, 1986;). Similarly, in Australia, under the guise of 'protectionism' mixed-race children were removed from their families into mission homes and non-indigenous foster homes and orphanages. As a result of government assimilationist policies on both sides of the globe, the forced removal of children from Indigenous parents and communities became known as 'The Stolen Generations.' Run by the churches in both countries there were chronic abuses of the children "in care" that are only now being acknowledged by their respective governments 
Hogue and Forrest

(Bombay, Matheson, \& Anison, 2014; Gray \& Beresford 2008). Both in Canada and Australia, the majority of Indigenous children suffered horrific physical and emotional atrocities, the effects of which have resulted in intergenerational trauma, social pathologies of maladjustment, family breakdown, suicide, alcoholism, domestic violence, and loss of parenting skills, to touch only the tip of the iceberg (Bombay et al., 2014; Gray \& Beresford 2008; TRC, 2015). In both countries, investigations into such schools have proven the “alleged" atrocities to be true, which have led to formal apologies in 2008 first by the Prime Minister of Australia, Kevin Rudd, followed a few months later by the Prime Minister of Canada, Stephen Harper. Outcomes of such atrocities have resulted in great distrust of the education system by the Indigenous peoples in both countries. Coupled to this, the paradigm clash between IWKL and those expected in the dominant Eurocentric-based education system have resulted in the extremely high leaving rates of Indigenous young people prior to school completion which precludes them from entering into post-secondary education (PSE). However, with the recent TRC in Canada (TRC, 2015) and a renewed drive for constitutional recognition for Indigenous peoples in Australia (Morris \& Pearson, 2017), there is a renewed focus on enabling the academic success of Indigenous students through university enabling programs such as the FNTP and PTS that bridge cultures in culturally relevant ways that attend to IWKL (Fredericks et al., 2017).

\section{IWKL and Digital Engagement}

Digital technology is the fastest changing ubiquitous tool used around the world and it is increasingly becoming the second language of education (Dudney, 2011). Such a tool may be even more beneficial for Indigenous youth who have historically struggled in the traditional Western education system of compartmentalized and siloed subjects in that, by its very nature of being hands-on, visual, inter-related, and integrated, it attends to IWKL.

Digital technologies allow one to interact with "the text," to learn and explore in a more 
engaged way, using it as a starting point for an adventure, a research project, or even a conversation with people. Embedded hypertext, texting as communication, and other types of digital literacy are as common to the digital generation as were books and photo albums to the parents of today's youth only a generation ago. One can explore and find information in ways that were impossible less than a decade ago. Digital technology, forever shape-shifting as an interfacing environment, is constantly providing opportunities and illustrations of relationships and inter-connections. It serves as a virtual tool to communicate across boundaries and gaps in creative ways that open up the liminal spaces of possibility. Similarly to Mack and Newberry as well as Navia in this collection, as educators we see digital technologies as a way of bridging cultures for Indigenous students in a way that the formal academic language, textbooks, and teaching methodologies of the Western education system have failed to do. Technology is hands-on learning-by-doing, so by its very nature it attends to IWKL and is key to our project of connecting Indigenous students in Australia with Indigenous students in Canada through a variety of digital modalities such that they can share their culture as well as their experiences of oscillating in that liminal space between cultures.

\section{The Pilot Project}

In the spring of 2017 in Lethbridge and the wet-to-beginning of the dry season in Darwin $^{3}$, we piloted our project by connecting students in our programs through Skype sessions. We wanted to get to know each other, share activities, develop workshops, create slideshows to share a sense of place and space, develop cultural understandings through

\footnotetext{
${ }^{3}$ Unlike Lethbridge where we experience four distinct seasons, Darwin's local Indigenous seasonal year is recognised in 7 main seasons: Balnba (rainy season), Dalay (monsoon season), Mayilema (speargrass, Magpie Goose egg and knock 'em down season), Damibila (Barramundi and bush fruit time), Dinidjanggama (heavy dew time), Gurrulwa (big wind time) and Dalirrgang (build-up). While the transitions out of and into these seasons might be equitable to our spring and fall seasons, most refer to only the wet, dry and build-up seasons in Darwin.
} 
Hogue and Forrest

conversation, and explore culture, indigeneity, dreams, and higher education aspirations. We chose Skype sessions so students could actually see each other and converse in real time. The Skype sessions had their own challenges in that we were working with polar opposite time zones where students were coming in early to class before 8 a.m. in Darwin (which is a day ahead) and staying after class until 5:30 p.m. in Lethbridge just to have an overlapping hour or two together. During the first Skype session, Darwin was on a cyclone watch and Lethbridge was in the middle of a blizzard. The wind was whipping through both landscapes in different ways and affecting the technology. In the second Skype session, it was $+35{ }^{\circ} \mathrm{C}$ and $100 \%$ humidity in Darwin and $-35^{\circ} \mathrm{C}$ with a mere $10 \%$ humidity and a 50 -km north wind in Lethbridge - quite the literal polarity. The students in Darwin were enamoured by the concept of a blizzard and snow they had never seen (they wanted to see pictures) and the students in Lethbridge were amazed, and envious, that it was so hot in Darwin on essentially the same day. In Darwin, we opted for huddling around Joanne’s laptop computer (Figure 1) as the conference technology failed, whereas in Lethbridge the Skype sessions took place in a large video-conference room (Figure 2). The willingness of the students to come in early in Darwin and stay late in Lethbridge and to persevere in spite of weather and technology highlighted their motivation to rise to the occasion to create and build relationships and maintain staying connected. Each of the sessions was video recorded and made available to each group for later reflection and future use.

We began the sessions with introductions. The students introduced themselves, where they were from, their family lineage, why they were taking their respective program, and their goals and aspirations. Interestingly, the lack of technology in Darwin turned out to be more beneficial in that the students each sat at the computer (see Figure 1) and introduced themselves and talked, so the image on the screen at the $U$ of $L$ was close and real and, in spite of students' Australian accents, much easier to hear. At the U of L, given the location of 
the camera and the spread of the students in the classroom, the image for the students in Darwin, especially on a laptop computer, was less personal and more difficult for them to see and hear, especially with Canadian accents. So we adjusted by having the students in the FNTP come to a point in front of the camera to do their introductions. While excited at building relationships, the students in both groups were nervous. When asked why they were nervous and shy, they said they did not know what to expect and they wanted to make a good impression. Both groups found it interesting that they had accents to each other and wondered what their accents really sounded like. "You don't think that you have an accent," an FNTP student said, “especially in Canada, but it makes sense that we would.” The FNTP students thought the Australians sounded somewhat British with much thicker accents and the PTS students thought the FNTP students sounded somewhat “American” but "nicer without the drawl.” Everyone found that funny. Another FNTP student said, “I really didn’t think we had an accent but they kept asking us to repeat what we said a bit slower. I thought it was cool to have an accent because they have very unique accents. You really want to know what you sound like.”

\section{Over-Under Student Reflections}

We had the students reflect on their experience after each session by journaling and sharing their thoughts with each other. After the first Skype session, one PTS student reflected,

When Joanne told us that we would link up with students from Canada, I was so excited as I would love to learn more about their history and themselves. So the next day as a group we all went into Joanne's office and we skyped/linked up with the Canadian First Nations' people. The students were so interesting, they were nervous just like us. Some were more confident than others. We all went around the room and introduced ourselves, and what we would love to do in the future. I was intrigued with their future goals as they were very interesting. I hope they achieve them. I was fascinated with some of the students' last names especially names like Eagle Bear and Shot Both Sides. They told the story of their names and I thought that was really cool. Interesting questions arose from Canada about a treaty and if we are still run by the government. It's funny because we do not know anything about their history and the same applies to them, but there are so many similarities. 


\section{An FNTP student commented,}

I was so excited to meet other Native students from the complete opposite side of the world. We only think of Natives in Canada and never really think there are others or that other Natives had the same experience as us. Even though there are big differences in comparison to environment, culture, language and traditions, there are similarities in terms of collectiveness, cultural integrity, and community-based structures. It fascinates me that their diet consists of kangaroo, turtles, clams, oysters, and other exotic meats. They thought eating deer, moose and buffalo was weird. I admit that standing up in front of everyone, and introducing myself was a tad awkward at first, but I enjoyed speaking to the people in Darwin because I got to express myself in a way that stood out from everyone. They were so interested in our culture. It's different because most times we feel our culture isn't part of education so we don't talk about it. I hope we can continue this.

The students in both countries were surprised at the similarity of the horrific history of attempted assimilation. Each thought it was isolated to their country alone, and their

historical and current experiences were unique to them. One student in the FNTP said,

How is it possible that the story is the same, or almost the same? It's like we are mirror images of each other; right and left-hand images. I feel so ripped off, like there was a global conspiracy against us. I think we need to share our stories, work together and build each other up; we need to support each other and cheer each other on so we can move forward and claim our rightful place in society. We each deserve equality and really, we shouldn't have to fight for it. It should be a no brainer.

The students in Darwin reflected that it was interesting to learn that there is a similar class on the other side of the world that holds similar values, passions and strengths. One Darwin student expressed it this way,

Personally, I really enjoyed the fact that when the students would introduce themselves, they would express how blessed they were to connect with us or how they counted their blessings to be able to meet us and hear our stories. Because of my Catholic faith I valued this as I too feel blessed to have the opportunity to connect with a class from across the world.

Another said, "this opportunity to build relationships by making connections, sharing career aspirations, stories of resilience, histories and cultures is a powerful motivator to learn. I want to know more and even go there.”

One Lethbridge student said,

It was great meeting the students and getting to know a bit about them. What surprised me was they mostly came from remote communities in Australia and didn't 
really know each other and they stayed at the university. I think it would be really hard to do that, to be that far from family. They are very brave and must really want their education to do that. It made me think we are very lucky here to have a university close to home and we often know at least a few people. Many of us know each other or know how we are connected to each other and that makes it somewhat easier I think.

The students in both countries collectively said, it was so interesting to talk to students who were experiencing the same things as us [summative]. One struggling FNTP student said, "It made me feel more normal, like it validated my own issues and challenges... in a sad kind of way.” Most said they thought, this [attempted assimilation and residential/mission schools] only happened to them and wondered how come they [schools] don't teach about the collective attempt to get rid of us [summative]. All were unaware of the over-under parallel story and asked, how did this happen? It's just wrong” [summative].

Throughout the sessions the students shared cultural practices, some of their cultural stories, foods they eat traditionally, and important ceremonies. In our final Skype session, former students in the FNTP shared traditional drumming and singing for the students in Darwin. They also described the making of the drum (Figure 3). The students in Darwin watched on computer and said they could only imagine how powerful it was in the real because even from that far away through the computer they felt the power of the drum and songs and were emotionally moved. One PTS student said, "the beat was so intense, I can only imagine how it was in the room. Thank you so much for sharing your culture.”

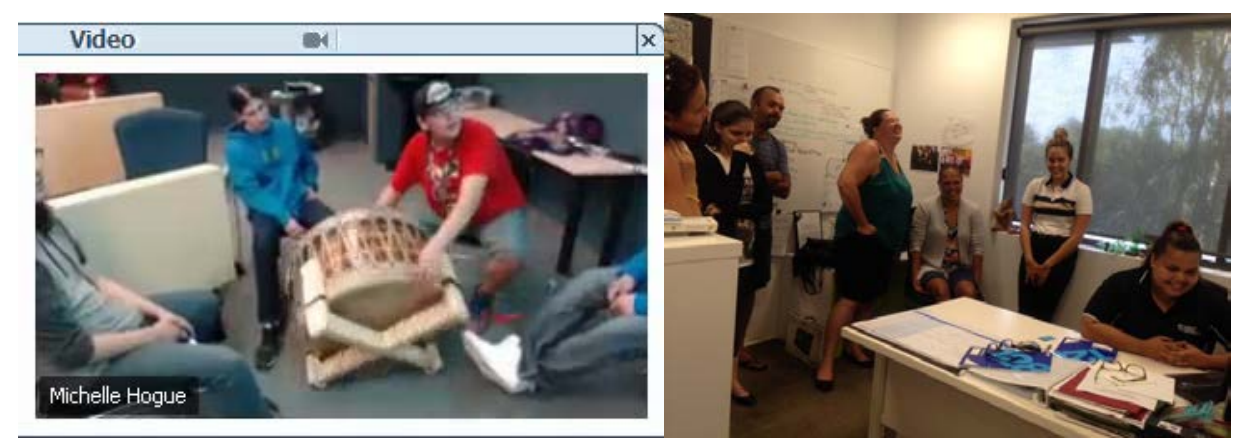

Figure 3. Sharing culture. 
Hogue and Forrest

In the final evaluations, all students said, this was one of the best learning experiences of the academic year and all hoped they could stay connected in the future [summative].

\section{Michelle and Joanne's Reflections}

While this was a challenging project to get up and running, the rewards have far outweighed the difficulties, and with a tentative start have been positively and deeply felt by both groups of students and also by us as educators. Currently there are more questions than answers, but there is a synergy and a willingness to keep connected and explore the relational learning and teaching space. Like Mack and Newberry and Navia in this collection, our collective experience has propelled the opening of what we believe to be a unique studentdriven engagement, where they as para-ethnographers (Rappaport, 2008) drive the agenda of research with their questions, and we as educators and researchers become the learners and listeners. As all in this collection have illustrated in their work, such co-creation and colearning is key to bridging cultures for students, educators, and institutes in this $21^{\text {st }}$ century of Reconciliation. The similarities in the Indigenous experience, the cultural values, the school and academic experience, and the drive to enter into and succeed at university, constantly surprise us; it appears to be a shared phenomenon over-under. Importantly is the desire to do this in a Two-Eyed Seeing, Both-Ways Learning way. Indigenous students overunder want an education, but they also want that to be inclusive of their ways of knowing and learning and their culture.

This connection is only the beginning of possibilities as the students learn more about each other and encourage each other in learning and realizing they are part of a larger global network from which they can draw strength. Moreover, this digital connection is vital for students to understand each other's histories and motivations to succeed in postsecondary/tertiary education. The opportunity to collaborate and share our experiences is leading us as educators to explore how students value each other's individual and collective 
personal histories and experiences of learning and identity and how that, in turn, might revision our learning and teaching design, methodology and pedagogy, as we move into the future of Indigenous academic success. Our over-under project resonates with Ober (2009) who writes that Both-Ways is not only a philosophy, but a practice of students remaining strong in their Indigenous identity whilst navigating the higher education domain. Both-Ways is the underpinning philosophy that drives the curriculum planning and pedagogical practice at Batchelor Institute in the Northern Territory, and it is the underpinning philosophy by which the PTS program was designed and how it is delivered. In Canada, given the recent TRC (2015) and the 94 Calls to Action, we are now beginning to move forward with the Two-Eyed Seeing philosophy, guiding principle and hard work of pioneers Dr. Cheryl Bartlett and Elders Albert and Murdena Marshall, who have struggled frustratingly uphill for more than two decades promoting this way of working collaboratively and relationally together. As Elder Albert Marshall says, this work of Two-Eyed Seeing is not easy, and so we need to understand that sometimes our most important job is to plant seeds for the future, for the youth, knowing seeds germinate when the time is right (Bartlett, 2017).

The time for this inclusive way of working together is finally right.

\section{Conclusion}

The benefits of our Bridging Cultures Over-Under project have far outweighed the challenges and draw our attention to the critical nature of relationship building in effective education, but in particular, Indigenous education. It is not only a way of working but a source of strength in co-learning, co-creating and collaborating together (Bartlett, 2017;

Ober, 2009; Rappaport, 2008). The process though, is not for the faint of heart as it is hard work that requires continual attention; it is truly about relationship-building, of working together as the prefix "co" implies. The liminal space between is a place of possibility that allows for the process of co-learning, learning together, to take place. 
Hogue and Forrest

The students have initiated the continuing of the conversation. It was suggested by the U of L students that we start a Facebook page to better get to know each other in a closed group online platform. In effect, this Facebook page may create a liminal space where students feel valued and comfortable enough with the each other to have deep conversations discussing their university experience, history, culture, and learning. Liminal, originating from the Latin limen, meaning threshold, aligns well with both transition-to-university programs where students are on the threshold of university degree studies whilst preparing for learning on university campuses. 'Liminality,' a transformational space (Land, Rattay, \& Vivian, 2014) is precisely what we aim to create and which is in line with the intention of both programs. There is the potential for strengthening of identity and for positive transformation by connecting with other Indigenous students with similar histories and aspirations across the globe. While their stories are unique, they are also similar and as Spring and Fox also illustrate in this collection, sharing stories provides a sense of validation, which can be the foundation for identity, empowerment and moving forward.

As Elder Albert Marshall says, co-learning is about nurturing collective relational capacities to understand and to collaborate. "It's about... learning together... with and from each other...” (Bartlett, 2017).

The authors wish to thank the students in the FNT and the PTS programs for their enthusiasm, dedication and continued perseverance in this project. As always, we learn from you.

E’kosi, Thank you, Michelle \& Joanne 


\section{References}

Bartlett, C., Marshall, M., \& Marshall, A. (2012). Two-eyed seeing and other lessons learned within a co-learning journey of bringing together Indigenous and mainstream knowledges and ways of knowing. Journal of Environmental Studies and Sciences, 2(4), 331-340.

Bartlett, C. (June 2017). Presentation for: Two-Eyed Seeing: Indigenous Peoples’ Advisory Board Meeting, Edmonton, AB: 19 June 2017 (Used with permission).

Bombay, A., Matheson, K., \& Anisman, H. (2014). The intergenerational effects of Indian Residential Schools: Implications for the concept of historical trauma. Transcultural Psychiatry, 51(3), 320-338.

Dudeney, G. (2011). No place in the classroom for digital illiteracies. The Guardian. https://www.theguardian.com/education/2011/dec/06/teaching-digital-literacy

Fredericks, B., Kinnear, S., Daniels, C., Croft-Warcon, P., \& Mann, J. (2017). Perspectives on enabling education for Indigenous students at three comprehensive universities in regional Australia. In Indigenous Pathways, Transitions and Participation in Higher Education (pp. 119-132). Singapore: Springer.

Getches, D., Wilkinson, C. \& Williams, R. (1993). Cases and Materials on Federal Indian Law ( ${ }^{\text {rd }}$ Ed.), St. Paul, MN: West Publishing Co.

Gray, J., \& Beresford, Q. (2008). A 'formidable challenge’: Australia's quest for equity in Indigenous education. Australian Journal of Education, 52(2), 197-223.

Howard-Wagner, D. \& Kelly, B. (2011). Containing Aboriginal mobility in the Northern Territory: From protectionism to interventionism. Law Text Culture, 15, 102.

Land, R., Rattray, J., \& Vivian, P. (2014). Learning in the liminal space: A semiotic approach to threshold concepts. Higher Education, 67(2), 199-217.

Merasty, J. (with Carpenter, D.; 2015). The education of Augie Merasty: A residential school memoir. Regina, MB: University of Regina Press.

Miller, J. (1989). Skyscrapers hide the heavens: A history of Indian-White relations in Canada. Toronto, ON: University of Toronto Press.

Morris, S. \& Pearson, N. (2017). Indigenous Constitutional Recognition: Paths to failure and possible paths to success. Australian Law Journal, 91(5), 350-359.

Ober, R. (2009). Both-ways: Learning from yesterday, celebrating today, strengthening tomorrow. The Australian Journal of Indigenous Education, 28, 232-265.

Ober, R., \& Bat, M. (2007). Paper 1: Both-ways: the philosophy. Ngoonjook, 31, 64.

O’Connor, P. (2000). Squaring the circle: How Canada is dealing with the legacy of its Residential Schools experiment. International Journal of Legal Information, 28, 232265. 
Hogue and Forrest

Rappaport, J. (2008). Beyond participant observation: Collaborative ethnography as theoretical innovation. Collaborative Anthropologies, 1, 1-31. doi: 10.01353/cla.0.0014

Singleton, G., Rola-Rubzen, M., Muir, K., Muir, D., \& McGregor, M. (2009). Youth empowerment and communication technologies: A case study of a remote Australian Aboriginal community. GeoJournal, 74(5), 403-413.

Titley, B. (1986). A narrow vision: Duncan Campbell Scott and the administration of Indian Affairs in Canada. British Columbia: University of British Columbia

Truth \& Reconciliation Commission of Canada (2015). Final report of the Truth and Reconciliation Commission of Canada volume one: Summary, honoring the reconciling for the future. Toronto: James Lorimer \& Co. Publishers.

Whithduck, J. (2010). Building the First Nations e-community. Aboriginal Policy Research Volume VI Setting the Agenda for Change, 6, 95-103. 